
\title{
$\begin{array}{ll}\text { Research Square } & \begin{array}{l}\text { Preprints are preliminary reports that have not undergone peer review. } \\ \text { They should not be considered conclusive, used to inform clinical practice, } \\ \text { or referenced by the media as validated information. }\end{array}\end{array}$
}

\section{The Effect of Early Vasopressin Use on Patients With Septic Shock: A Systematic Review and Meta-analysis}

\author{
Haijun Huang \\ The First Affiliated Hospital of Zhejiang Chinese Medical University \\ Chenxia Wu \\ The First Affiliated Hospital of Zhejiang Chinese Medical University \\ Qinkang Shen \\ The First Affiliated Hospital of Zhejiang Chinese Medical University \\ Hua Xu \\ THE FIRST AFFILIATED HOSPITAL OF ZHEJIANG CHINESE MEDICAL UNIVERSITY \\ Yixin Fang \\ THE FIRST AFFILIATED HOSPITAL OF ZHEJIANG CHINESE MEDICAL UNIVERSITY \\ Wei Mao ( $\sim$ hzhizhen123@yeah.net) \\ Department of Emergency, The First Affiliated Hospital of Zhejiang Chinese Medical University, Zhejiang 310018, Hangzhou, China
}

\section{Research}

Keywords: early, Vasopressin initiation, Septic shock, Systematic review, Meta-analysis

Posted Date: November 2nd, 2020

DOl: https://doi.org/10.21203/rs.3.rs-99744/v1

License: (c) (i) This work is licensed under a Creative Commons Attribution 4.0 International License. Read Full License

Version of Record: A version of this preprint was published at The American Journal of Emergency Medicine on October 1st, 2021. See the published version at https://doi.org/10.1016/j.ajem.2021.05.007. 


\section{Abstract}

Background: The effect of early vasopressin initiation on clinical outcomes in patients with septic shock is uncertain. A systematic review and metaanalysis was performed to evaluate the impact of early start of vasopressin support within 6 hours after the diagnosis on clinical outcomes in septic shock patients.

Methods: We searched the PubMed, Cochrane, and Embase databases for randomized controlled trials (RCTs) and cohort studies from inception to the 1st of October 2020. We included studies involving adult patients ( $>16$ years)with septic shock. All authors reported our primary outcome of short-term mortality and in the experimental group patients in the studies receiving vasopressin infusion within 6 hours after diagnosis of septic shock and in the control group patients in the studies receiving no vasopressin infusion or vasopressin infusion 6 hours after diagnosis of septic shock, clearly comparing with clinically relevant secondary outcomes(use of renal replacement therapy(RRT),new onset arrhythmias, ICU length of stay and length of hospitalization). Results were expressed as odds ratio (OR) and mean difference (MD) with accompanying $95 \%$ confidence interval (CI).

Results: Five studies including 788 patients were included. The primary outcome of this meta-analysis showed that short-term mortality between the two groups was no difference (odds ratio $[\mathrm{OR}]=1.09 ; 95 \% \mathrm{Cl}, 0.8$ to $1.48 ; \mathrm{P}=0.6 ; \chi 2=0.83 ; 12=0 \%$ ). Secondary outcomes demonstrated that the use of RRT was less in the experimental group than that of the control group $(\mathrm{OR}=0.63 ; 95 \% \mathrm{Cl}, 0.44$ to $0.88 ; \mathrm{P}=0.007 ; \chi 2=3.15 ; \mathrm{I} 2=36 \%)$. The new onset arrhythmias between the two groups was no statistically significant difference $(\mathrm{OR}=0.59 ; 95 \% \mathrm{Cl}, 0.31$ to $1.1 ; \mathrm{P}=0.10 ; \chi 2=4.7 ; 12=36 \%)$. There was no statistically significant difference in the ICU length of stay (mean difference $=0.16 ; 95 \% \mathrm{Cl},-0.91$ to $1.22 ; \mathrm{P}=0.77 ; \chi 2=6.08 ; \mathrm{I} 2=34 \%$ ) and length of hospitalization (mean difference $=-2.41 ; 95 \% \mathrm{Cl},-6.61$ to $1.78 ; \mathrm{P}=0.26 ; \chi 2=8.57 ; \mathrm{I} 2=53 \%$ ) between the two groups.

Conclusions: Early initiation of vasopressin in patients within 6 hours of septic shock onset was not associated with decreased short-term mortality, new onset arrhythmias, shorter ICU length of stay and length of hospitalization, but can reduce the use of RRT. Further large-scale RCTs are still needed to evaluate the benefit of starting vasopressin in the early phase of septic shock.

\section{Introduction}

Septic shock, which is characterized by severe hemodynamic failure, remains a major challenge associated with $30 \%$ to $40 \%$ hospital mortality, even though important therapeutic advances have been made over the past decades[1]. The essential step in the management of patients with septic shock is to increase systemic and regional/microcirculatory flow. Increasing arterial blood pressure with vasopressors when patients are hypotensive is used to improve the input pressure driving organ perfusion. The Surviving Sepsis Campaign (SSC) guidelines recommend norepinephrine as the first-line vasoactive agent in patients presenting with septic shock[2]. Vasopressin is recommended as a second-line vasopressor by the SSC[2]

This is a weak recommendation[2], owing significantly to the lack of improvement in mortality when vasopressin was added to norepinephrine in patients experiencing septic shock in a large randomized trial of vasopressin versus norepinephrine in patients with septic shock(VASST) [3]. However, vasopressin was not initiated until almost 12 hours after study criteria were met, which may have adversely affected its potential impact on patient outcomes. Pilot studies have more recently evaluated earlier initiation of vasopressin with or not with norepinephrine, and observed encouraging findings[4-6], including improvements of renal function[5] and sequential organ failure assessment (SOFA) scores[6] at 48 and 72 hours after admission and fewer episodes of new-onset arrhythmias[4]. Studies from Wu et al[7] and Bauer SR. et al [8] observed no difference in the time to achieve target mean arterial pressure MAP but a benefit in mortality[7] if delay in the start of vasopressin. A large interventional study did not find a benefit in kidney failure-free days or mortality with earlier use of vasopressin[9].

The purpose of this meta-analysis was to evaluate the impact of early start of vasopressin support within 6 hours after the diagnosis on clinical outcomes in septic shock patients.

\section{Methods}

The present meta-analysis was performed and reported according to the Preferred

Reporting Items for Systematic Reviews and Meta-Analyses (PRISMA)[10]

\section{Registration and protocol}

This meta-analysis was registered on PROSPERO(CRD42020206103)

\section{Data source and literature search}

We searched the PubMed, Cochrane, and Embase databases for studies from inception to the 1st of October 2020 using the following search terms: timing, time, early, earlier, delay, late, initiation, start, vasopressin, and septic shock. The search was slightly adjusted according to the requirements of the different databases. All of the review articles and cross-referenced studies from the retrieved articles were screened for pertinent information. The flow chart of the search strategies is summarized in Fig.1.

Types of outcome measures 
The primary outcome was short-term mortality; short-term mortality included hospital mortality, 28-day mortality. The secondary endpoints included use of renal replacement therapy (RRT), new onset arrhythmias, ICU length of stay and length of hospitalization,

\section{Study selection and data extraction}

The inclusion criteria were as follows: (1) adult patients (> 16 years) with septic shock, septic shock was classified according to the current Third International Consensus Definitions for Sepsis and Septic Shock (Sepsis3.0), which considers the presence of suspected infection accompanying organ dysfunction, the use of vasopressors, MAP $<65 \mathrm{mmHg}$, and lactate levels $>2 \mathrm{mmol} / \mathrm{L}[11]$; (2) RCTs as well as prospective and retrospective cohort studies comparing adult septic shock patients receiving vasopressin infusion within 6 hours after diagnosis of septic shock compared with patients receiving no vasopressin infusion or vasopressin infusion 6 hours after diagnosis of septic shock; (3) all authors reported our primary outcome of short-term mortality; patients in the studies receiving vasopressin infusion within 6 hours after diagnosis of septic shock in the experimental group and receiving no vasopressin infusion or vasopressin infusion 6 hours after diagnosis of septic shock in the control group,clearly comparing with clinically relevant secondary outcomes. We excluded review or conference abstract articles and studies about pediatric or animal.

\section{Study quality evaluation}

Two reviewers independently performed quality assessment. The quality of studies was assessed using the Cochrane Collaboration's tool for RCTs [12]and the Newcastle Ottawa Scale (NOS) was used for cohort studies[13]. The risk of bias summary for included RCT is presented in Fig.2; the risk of bias graph for included RCT is presented in Fig.3.

NOS allocates a maximum of 9 points according to the quality of the selection, comparability, and outcomes of the cohort study populations. Study quality was defined as poor (0-3), fair (4-6), or good (7-9). The quality of the included cohort studies is presented in Table 1.

\section{Statistical analysis}

Statistical analyses were performed using Review Manager version 5.3 (RevMan, The Cochrane Collaboration,Oxford, UK). Odds ratio (OR) with 95\% confidence intervals $(\mathrm{Cl})$ was calculated for dichotomous variables. As to the continuous variables, mean difference (MD) and $95 \% \mathrm{Cl}$ were estimated as the effect result. A random effects model was used to pool studies with significant heterogeneity, as determined by the chi-squared test $(\mathrm{P}<0.10)$ and inconsistency index $\left(I^{2} \geq 50 \%\right)$ [14]. Some of the selected continuous variables were represented by the median (interquartile range). We calculated their mean and standard deviation according to the sample size with a calculator [15] and then performed a meta-analysis. A P value $<0.05$ was set as the threshold of statistical significance.

\section{Results}

\section{Study characteristics}

The search strategy identified 876 studies, and the data were from 1 RCT and 4 cohort studies comprising 788 patients (Table 2)[4, 9, 16-18]. The characteristics of the included studies are shown in Table 2. A total of 5 eligible studies were published between 2013 and 2019 .Among these studies, one study was conducted in UK, all other studies were conducted in the USA. In addition to a multicenter randomized controlled study, the other four studies were single center prospective or retrospective cohort studies.

\section{Primary outcome}

A total of five studies including 788 patients were included, and the short-term mortality was about 38.3\% (154/394 in the experimental group and 148/394 in the control group). There was no difference in short-term mortality between the two groups (odds ratio $[\mathrm{OR}]=1.09 ; 95 \% \mathrm{Cl}, 0.8$ to $1.48 ; \mathrm{P}=0.6 ; \chi^{2}=0.83 ; \mathrm{I}^{2}$ $=0 \%$ ) (Fig. 4). A funnel plot was used to assess the publication bias (Fig. 5).

\section{Secondary outcomes}

Use of RRT

Three of the included studies were analyzed to assess the use of RRT. the use of RRT was less in the experimental group than that of the control group (OR $=0.63 ; 95 \% \mathrm{Cl}, 0.44$ to $0.88 ; \mathrm{P}=0.007 ; \chi^{2}=3.15 ; \mathrm{I}^{2}=36 \%$ ) (Fig. 6$)$.

\section{New onset arrhythmias}

Four of the included studies were analyzed to assess the new onset arrhythmias. The new onset arrhythmias between the two groups was no statistically significant difference ( $\mathrm{OR}=0.59 ; 95 \% \mathrm{Cl}, 0.31$ to $1.1 ; \mathrm{P}=0.10 ; \chi^{2}=4.7 ; \mathrm{I}^{2}=36 \%$ ) (Fig. 7).

\section{ICU length of stay}

All of included studies were analyzed to assess the ICU length of stay (day).

There was no statistically significant difference in the ICU length of stay between the two groups $\left(\mathrm{MD}=0.16 ; 95 \% \mathrm{Cl},-0.91\right.$ to $1.22 ; \mathrm{P}=0.77 ; \chi^{2}=6.08 ; \mathrm{I}^{2}$ $=34 \%$ ) (Fig. 8). 
All of included studies were analyzed to assess the length of hospitalization (day). There was no statistically significant difference in the length of hospitalization between the two groups (MD $=-2.41 ; 95 \% \mathrm{Cl},-6.61$ to $1.78 ; \mathrm{P}=0.26 ; \chi^{2}=8.57 ; \mathrm{I}^{2}=53 \%$ ) (Fig. 9). The result of the study by Reardon[4] was different from the other studies. A sensitive analysis was performed by removing the study by Reardon,the combined $\mathrm{MD}$ was -3.75 ( $95 \% \mathrm{Cl}-7.81$ to $\left.-0.31 ; P=0.07 ; l^{2}=39 \%\right)$.

\section{Discussion}

This systematic review and meta-analysis of five studies including 788 patients evaluated the impact of early start of vasopressin support on clinical outcomes in septic shock patients within 6 hours after the diagnosis. We found that the overall short-term mortality was about $38.3 \%$, there were no statistically significant difference in the short-term mortality, new onset arrhythmias, ICU length of stay and length of hospitalization between the experimental group and control group, the use of RRT was lower in the experimental group.

Vasopressin is a neurohypophyseal hormone with diverse actions mediated by tissue-specific receptors. The rationale for using vasopressin is the development of relative vasopressin deficiency in patients with septic shock and the observation that low dose vasopressin infusion improves blood pressure, decreases requirements for catecholamines and improves renal function[19]. From a retrospective cohort study [20],it revealed that 17.2\% of patients with septic shock in United States hospitals received vasopressin. In the ADRENAL trial[21], which included patients from Australia, the United Kingdom, New Zealand, Saudi Arabia, and Denmark, usage was similar with $16.8 \%$ of patients receiving vasopressin at baseline.

Vasopressin levels vary during the different stages of septic shock[22], therefore, timing of vasopressin initiation could play a critical role in septic shock management.

In the VASST trial[3], vasopressin was not associated with improved mortality as compared with norepinephrine but when mortality rates were stratified into patients who received early vasopressin $(\leq 12 \mathrm{~h})$, rates were higher in the norepinephrine group $(40.5 \%$ vs. $33.2 \%, P=0.12)$, initiation of vasopressin within 12 hours could

have been delayed because plasma vasopressin levels were extremely low as early as 6 hours[22].In this meta-analysis, we do not find improved short-term mortality when vasopressin initiated within 6 hours of septic shock onset. Though early initiation of vasopressin in patients with septic shock may achieve and maintain goal MAP sooner[16, 18],surrogate end points evaluated, such as time to goal MAP, failed to translate to a mortality benefit.

Acute kidney injury (AKI) is a common complication of sepsis and septic shock. a post hoc analysis of VASST [23] demonstrated that patients at risk for AKI development according to the Risk, Injury,Failure, Loss of kidney function, and End-stage kidney disease (RIFLE) criteria, who received vasopressin within 12 hours of shock onset had a lower rate of progression to renal failure or loss categories ( $21 \%$ vs $40 \%$, respectively; $P=0.03)$ and a lower need for RRT $(17 \%$ vs $38 \%, P=0.02)$. In the VANISH trial[9], the early use of vasopressin compared with norepinephrine did not improve the number of kidney failure-free days, Patients in the vasopressin group were less likely to receive RRT compared with the norepinephrine group $(25 \%$ vs $35 \%$, P $=0.03)$. In our meta-analysis we found the use of RRT was less in the experimental group than that of the control group. A recent meta-analysis [24]focused on renal outcomes in distributive shock patients who received vasopressin or terlipressin, demonstrated patients who received vasopressin or terlipressin had reduced need for RRT and lower incidence of AKI. However, significant heterogeneity in the studies existed, and the lower incidence of AKI and use of RRT with vasopressin analogues was lost in the septic shock patients.

Catecholamine use has been linked to both an increased incidence of arrhythmias and increased cardiac ischemia[25]. In our meta-analysis we found no reduced new onset arrhythmias when vasopressin initiated within 6 hours of septic shock onset. However, the definition of arrhythmias of the included studies was different, which might render an unsolvable bias. In addition, our meta-analysis showed that there was no statistically significant difference in the ICU length of stay and length of hospitalization between the two groups.

Several limitations should be taken into consideration when interpreting our findings. Firstly, by the nature of meta-analysis in general, the results of this paper were dependent on the quality of available studies. There are only one RCT study included, other four included studies were small-scale single center cohort studies. The results and conclusions should therefore be interpreted with caution. Second, we did not perform a subgroup analysis of RCT and cohort studies, very heterogeneous populations were included in both randomized and observational studies. Third, mean arterial pressure and organ dysfunction is also a very important clinical outcome. However, few included studies had shown this data. In addition, inclusion/exclusion criteria and vasopressin dosage were widely different among included studies which supposed a limitation to interpret results. Therefore, our findings should be interpreted with caution.

\section{Conclusion}

Early initiation of vasopressin in patients within 6 hours of septic shock onset was not associated with decreased short-term mortality, new onset arrhythmias, shorter ICU length of stay and length of hospitalization, but can reduce the use of RRT. Further large-scale RCTs are still needed to evaluate the benefit of starting vasopressin in the early phase of septic shock.

\section{List Of Abbreviations}

MAP: Mean arterial pressure

SSC: Surviving Sepsis Campaign

Page $4 / 11$ 
RCTs: Randomized controlled trials

ICU: Intensive care unit

SOFA: Sequential organ failure assessment

RRT: Renal replacement therapy

PRISMA: Preferred Reporting Items for Systematic Reviews and Meta-Analyses

NOS: Newcastle-Ottawa Scale

OR: Odds ratio

MD: Mean difference

Cl: Confidence interval

AKI: Acute kidney injury

\section{Declarations}

\section{Ethics approval and consent to participate}

Not applicable.

\section{Consent for publication}

Not applicable.

\section{Availability of data and material}

The datasets used and/or analysed during the current study are available from the corresponding author on reasonable request.

Competing interests

All authors declare that they have no any conflict of interests.

\section{Funding}

This work was supported by Zhejiang Traditional Chinese Medicine Science and Technology Project(NO. 2020ZA046)

\section{Authors' contributions}

Haijun Huang and Wei Mao carried out the studies, participated in collecting data, and drafted the manuscript. Chenxia Wu and Qinkang Shen performed the statistical analysis and participated in its design. Yixin Fang and Hua Xu helped to draft the manuscript. All authors read and approved the final manuscript.

\section{Acknowledgements}

None.

\section{References}

1. Vincent J-L, Jones G, David S, Olariu E, Cadwell KK: Frequency and mortality of septic shock in Europe and North America: a systematic review and meta-analysis. Critical care (London, England) 2019, 23(1):196.

2. Rhodes A, Evans LE, Alhazzani W, Levy MM, Antonelli M, Ferrer R, Kumar A, Sevransky JE, Sprung CL, Nunnally ME et al: Surviving Sepsis Campaign: International Guidelines for Management of Sepsis and Septic Shock: 2016. Intensive Care Medicine 2017, 43(3):304-377.

3. Russell JA, Walley KR, Singer J, Gordon AC, Hébert PC, Cooper DJ, Holmes CL, Mehta S, Granton JT, Storms MM et al: Vasopressin versus norepinephrine infusion in patients with septic shock. N Engl J Med 2008, 358(9):877-887.

4. Reardon DP, DeGrado JR, Anger KE, Szumita PM: Early vasopressin reduces incidence of new onset arrhythmias. J Crit Care 2014, 29(4):482-485.

5. Lauzier F, Lévy B, Lamarre P, Lesur O: Vasopressin or norepinephrine in early hyperdynamic septic shock: a randomized clinical trial. Intensive Care Med 2006, 32(11):1782-1789.

6. Bihari D, Prakash S, Bersten A: Low-dose vasopressin in addition to noradrenaline may lead to faster resolution of organ failure in patients with severe sepsis/septic shock. Anaesth Intensive Care 2014, 42(5):671-674. 
7. Wu JY, Stollings JL, Wheeler AP, Semler MW, Rice TW: Efficacy and Outcomes After Vasopressin Guideline Implementation in Septic Shock. Ann Pharmacother 2017, 51(1):13-20.

8. Bauer SR, Sacha GL, Reddy AJ: Mortality, Morbidity, and Costs After Implementation of a Vasopressin Guideline in Medical Intensive Care Patients With Septic Shock: An Interrupted Time Series Analysis. Ann Pharmacother 2020, 54(4):314-321.

9. Gordon AC, Mason AJ, Thirunavukkarasu N, Perkins GD, Cecconi M, Cepkova M, Pogson DG, Aya HD, Anjum A, Frazier GJ et al: Effect of Early Vasopressin vs Norepinephrine on Kidney Failure in Patients With Septic Shock: The VANISH Randomized Clinical Trial. Jama 2016, 316(5):509-518.

10. Moher D, Liberati A, Tetzlaff J, Altman DG: Preferred reporting items for systematic reviews and meta-analyses: the PRISMA statement. Bmj 2009, 339:b2535.

11. Singer M, Deutschman CS, Seymour CW, Shankar-Hari M, Annane D, Bauer M, Bellomo R, Bernard GR, Chiche JD, Coopersmith CM et al: The Third International Consensus Definitions for Sepsis and Septic Shock (Sepsis-3). Jama 2016, 315(8):801-810.

12. JPT. H, J. T, J. C, M. C, T. L, MJ. P, . WV: Cochrane Handbook for Systematic Reviews of Interventions version 6.1 (updated September 2020 ).Cochrane, 2020. Available from www.training.cochrane.org/handbook.

13. Wells G, Shea B, O'Connell J: The Newcastle-Ottawa Scale (NOS) for Assessing The Quality of Nonrandomised Studies in Meta-analyses. Ottawa Health Research Institute Web site 2014, 7.

14. Biggerstaff BJ, Jackson D: The exact distribution of Cochran's heterogeneity statistic in one-way random effects meta-analysis. Stat Med 2008, 27(29):6093-6110.

15. Wan X, Wang W, Liu J, Tong T: Estimating the sample mean and standard deviation from the sample size, median, range and/or interquartile range. BMC Med Res Methodol 2014, 14:135.

16. Hammond DA, Cullen J, Painter JT, McCain K, Clem OA, Brotherton AL, Chopra D, Meena N: Efficacy and Safety of the Early Addition of Vasopressin to Norepinephrine in Septic Shock. $J$ Intensive Care Med 2019, 34(11-12):910-916.

17. Hammond DA, Ficek OA, Painter JT, McCain K, Cullen J, Brotherton AL, Kakkera K, Chopra D, Meena N: Prospective Open-label Trial of Early Concomitant Vasopressin and Norepinephrine Therapy versus Initial Norepinephrine Monotherapy in Septic Shock. Pharmacotherapy 2018, 38(5):531538.

18. Daley MJ, Lat I, Mieure KD, Jennings HR, Hall JB, Kress JP: A comparison of initial monotherapy with norepinephrine versus vasopressin for resuscitation in septic shock. Ann Pharmacother 2013, 47(3):301-310.

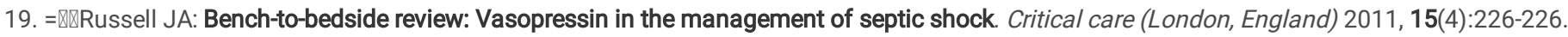

20. Vail EA, Gershengorn HB, Hua M, Walkey AJ, Wunsch H: Epidemiology of Vasopressin Use for Adults with Septic Shock. Annals of the American Thoracic Society 2016, 13(10):1760-1767.

21. Venkatesh B, Finfer S, Cohen J, Rajbhandari D, Arabi Y, Bellomo R, Billot L, Correa M, Glass P, Harward M et al: Adjunctive Glucocorticoid Therapy in Patients with Septic Shock. N Engl J Med 2018, 378(9):797-808.

22. Sharshar T, Blanchard A, Paillard M, Raphael JC, Gajdos P, Annane D: Circulating vasopressin levels in septic shock. Crit Care Med 2003, 31(6):17521758.

23. Gordon AC, Russell JA, Walley KR, Singer J, Ayers D, Storms MM, Holmes CL, Hébert PC, Cooper DJ, Mehta S et al: The effects of vasopressin on acute kidney injury in septic shock. Intensive Care Med 2010, 36(1):83-91.

24. Nedel WL, Rech TH, Ribeiro RA, Pellegrini JAS, Moraes RB: Renal Outcomes of Vasopressin and Its Analogs in Distributive Shock: A Systematic Review and Meta-Analysis of Randomized Trials. Crit Care Med 2019, 47(1):e44-e51.

25. De Backer D, Biston P, Devriendt J, Madl C, Chochrad D, Aldecoa C, Brasseur A, Defrance P, Gottignies P, Vincent JL: Comparison of dopamine and norepinephrine in the treatment of shock. N Engl J Med 2010, 362(9):779-789.

\section{Tables}

Table 1 Quality of the included cohort studies (The Newcastle-Ottawa Scale) 


\begin{tabular}{|c|c|c|c|c|c|c|c|c|c|}
\hline \multirow[t]{2}{*}{ Study } & \multicolumn{4}{|l|}{ Selection } & \multirow{2}{*}{$\begin{array}{l}\text { Comparability } \\
\text { Comparability } \\
\text { of cohorts on } \\
\text { the basis of } \\
\text { the design or } \\
\text { analysis }\end{array}$} & \multicolumn{4}{|l|}{ Outcome } \\
\hline & $\begin{array}{l}\text { Representativeness } \\
\text { of the exposed } \\
\text { cohort }\end{array}$ & $\begin{array}{l}\text { Selection } \\
\text { of the } \\
\text { non- } \\
\text { exposed } \\
\text { cohort }\end{array}$ & $\begin{array}{l}\text { Ascertainment } \\
\text { of exposure }\end{array}$ & $\begin{array}{l}\text { Demonstration } \\
\text { that outcome } \\
\text { of interest was } \\
\text { not present at } \\
\text { start of study }\end{array}$ & & $\begin{array}{l}\text { Assessment } \\
\text { of outcome }\end{array}$ & $\begin{array}{l}\text { Was } \\
\text { follow-up } \\
\text { long } \\
\text { enough } \\
\text { for } \\
\text { outcomes } \\
\text { to occur }\end{array}$ & $\begin{array}{l}\text { Adequacy } \\
\text { of follow } \\
\text { up of } \\
\text { cohorts }\end{array}$ & $\begin{array}{l}\text { Total } \\
\text { score }\end{array}$ \\
\hline $\begin{array}{l}\text { Daley } \\
2013\end{array}$ & प & प & प & प & $\nabla \nabla$ & प & प & प & 9 \\
\hline $\begin{array}{l}\text { Reardon } \\
2014\end{array}$ & Q & प & प & Q & $\nabla \nabla$ & प & प & Q & 9 \\
\hline $\begin{array}{l}\text { Hammond } \\
2018\end{array}$ & $\square$ & Q & प & प & $\nabla \nabla$ & प & प & प & 9 \\
\hline $\begin{array}{l}\text { Hammond } \\
2019\end{array}$ & $\square$ & प & प & Q & $\nabla \nabla$ & 口 & प & प & 9 \\
\hline
\end{tabular}

Table 2. The basic characteristics of studies included in the meta-analysis

\begin{tabular}{|c|c|c|c|c|c|c|c|}
\hline Trial & Year & Country & Study design & $\begin{array}{l}\text { Sample } \\
\text { size }\end{array}$ & Study period & Experimental group & Control group \\
\hline Daley 2013 & 2013 & USA & $\begin{array}{l}\text { Single center } \\
\text { retrospective cohort }\end{array}$ & 130 & $\begin{array}{l}\text { May 2008- } \\
\text { Sep.2009 }\end{array}$ & vasopressin & norepinephrine \\
\hline $\begin{array}{l}\text { Reardon } \\
2014\end{array}$ & 2014 & USA & $\begin{array}{l}\text { Single center } \\
\text { retrospective cohort }\end{array}$ & 71 & $\begin{array}{l}\text { Jan. } 2010 \text { - } \\
\text { Dec. } 2011\end{array}$ & $\begin{array}{l}\text { early vasopressin and } \\
\text { catecholamines }\end{array}$ & $\begin{array}{l}\text { later vasopressin and } \\
\text { catecholamines }\end{array}$ \\
\hline $\begin{array}{l}\text { Gordon } \\
2016\end{array}$ & 2016 & UK & multicenter RCT & 409 & $\begin{array}{l}\text { Feb. } 2013 \text { - } \\
\text { May } 2015\end{array}$ & vasopressin & norepinephrine \\
\hline $\begin{array}{l}\text { Hammond } \\
2018\end{array}$ & 2018 & USA & $\begin{array}{l}\text { Single center } \\
\text { prospective cohort }\end{array}$ & 82 & $\begin{array}{l}\text { Nov.2015-Jun. } \\
2016\end{array}$ & $\begin{array}{l}\text { vasopressin and } \\
\text { norepinephrine }\end{array}$ & norepinephrine \\
\hline $\begin{array}{l}\text { Hammond } \\
2019\end{array}$ & 2019 & USA & $\begin{array}{l}\text { Single center } \\
\text { retrospective cohort }\end{array}$ & 96 & $\begin{array}{l}\text { May 2014- Oct. } \\
2015\end{array}$ & $\begin{array}{l}\text { vasopressin and } \\
\text { norepinephrine }\end{array}$ & norepinephrine \\
\hline
\end{tabular}

\section{Figures}




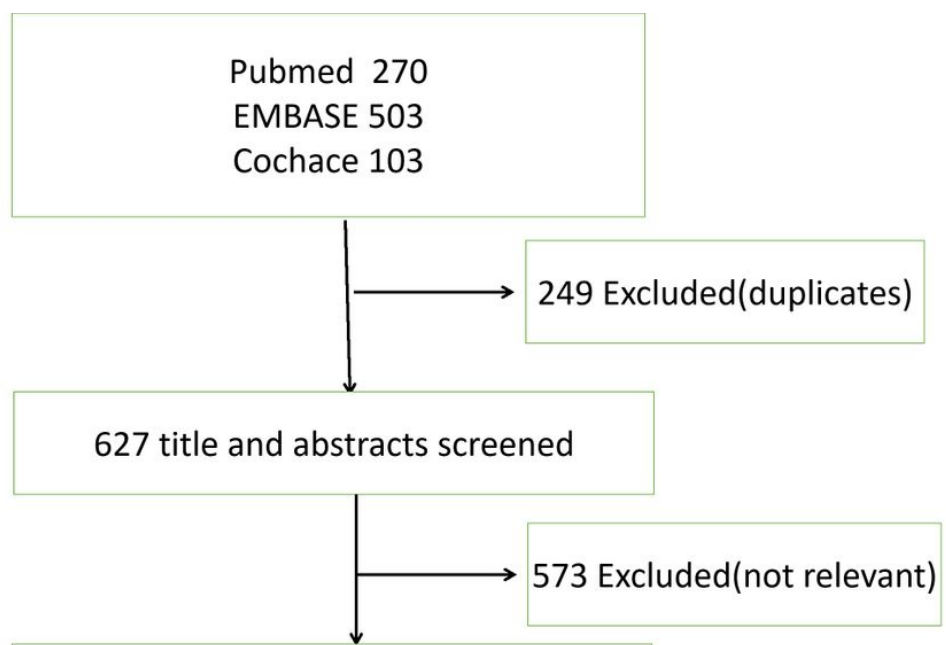

54 Full-text articles assessed for eligibility

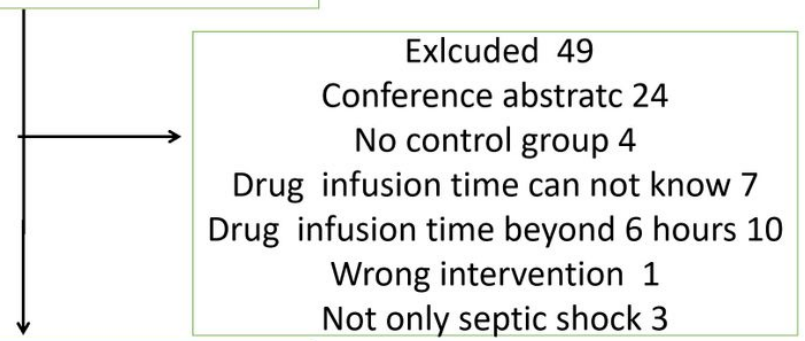

Studies included in qualitative synesis 5

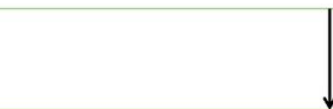

Studies included in qualitative synesis

meta-analysis 5

Figure 1

Flow chart of literature selection. 


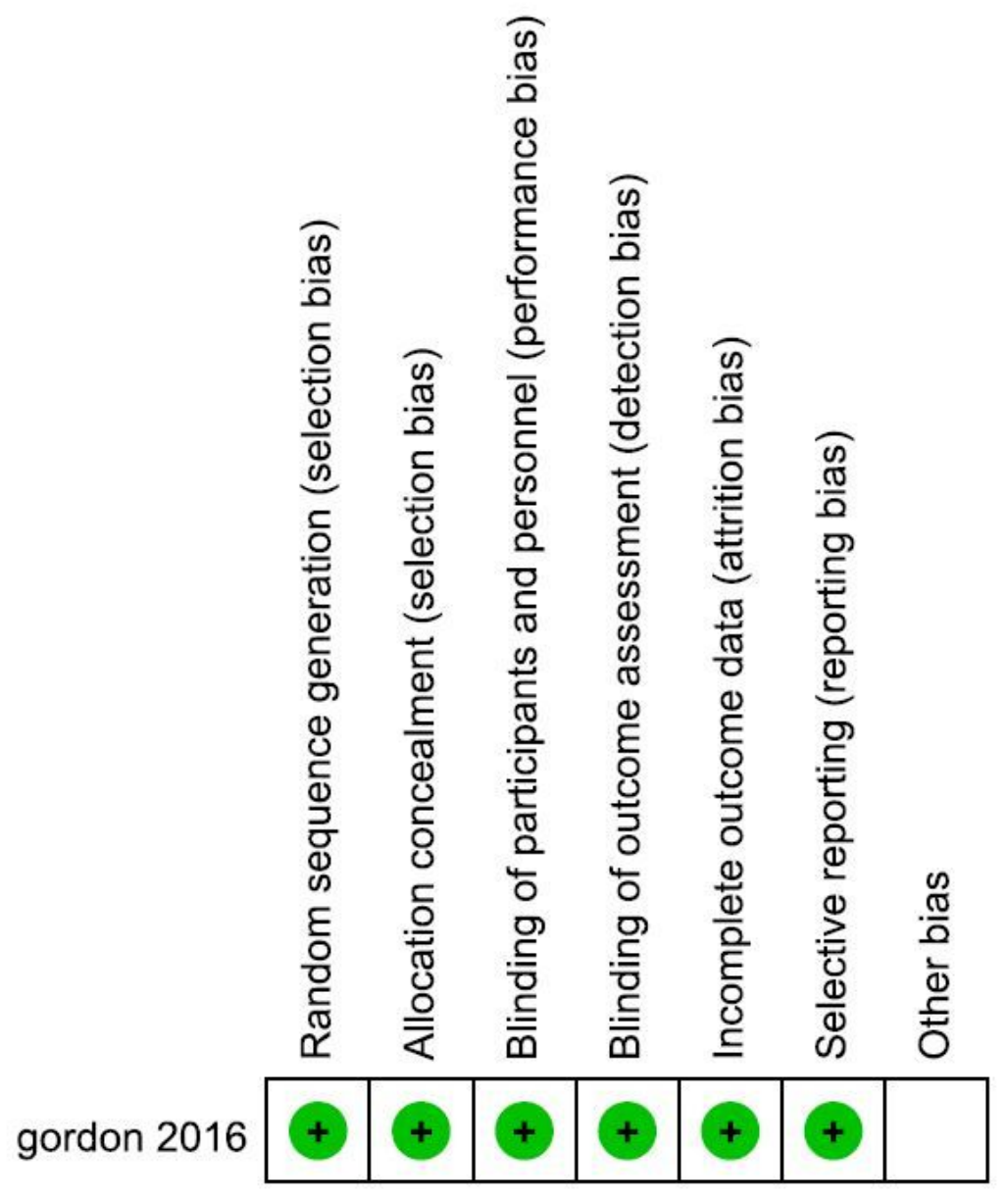

Figure 2

The risk of bias summary for included RCT .

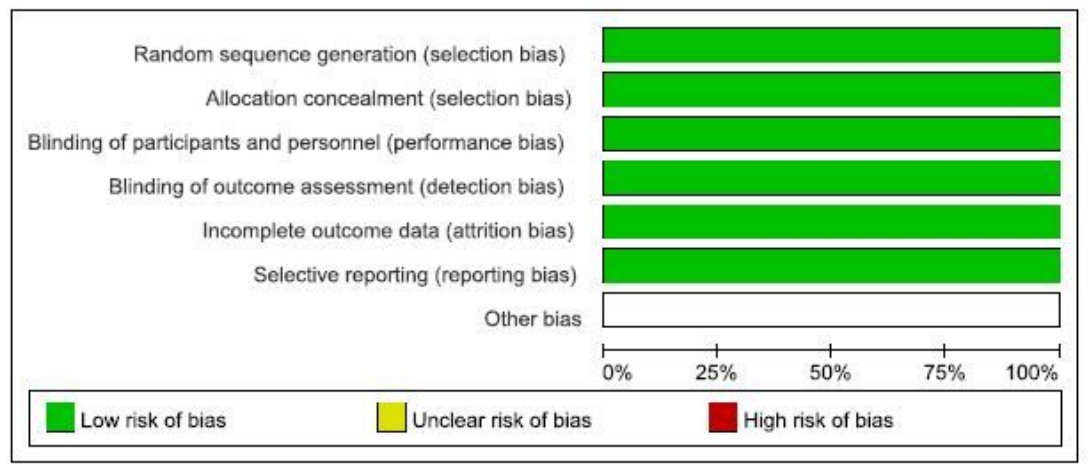

Figure 3

The risk of bias graph for included RCT. 


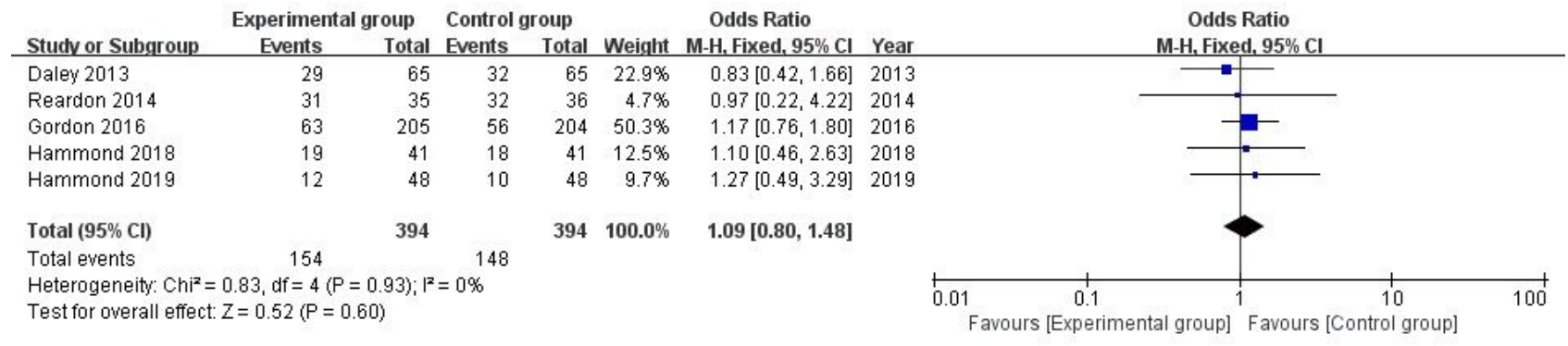

\section{Figure 4}

Forest plot for short-term mortality.

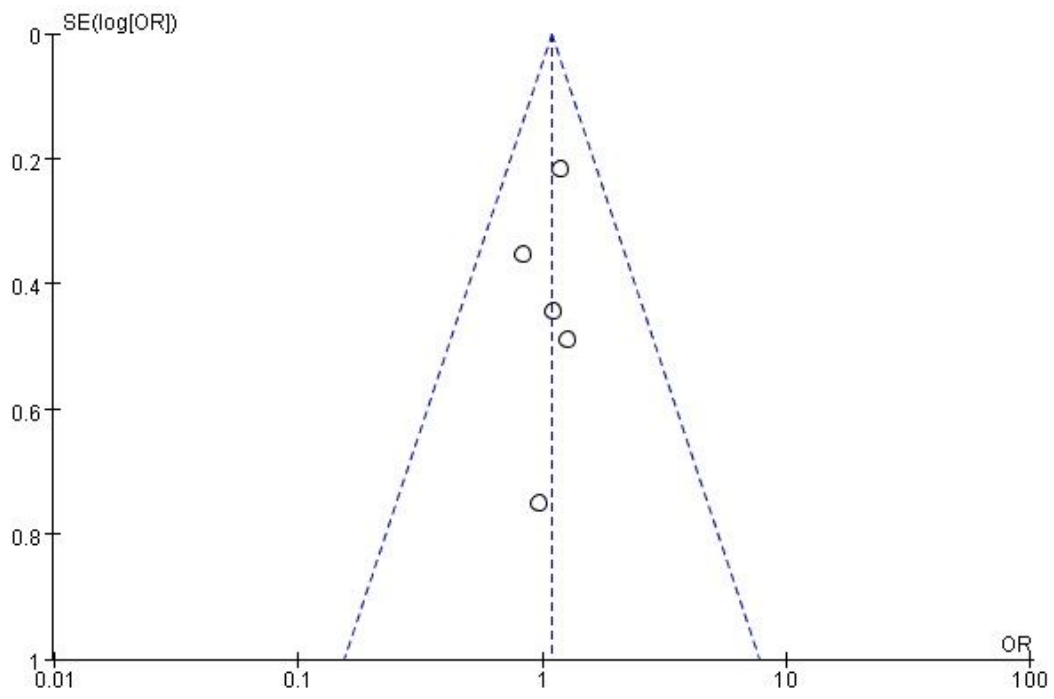

\section{Figure 5}

Funnel plot for short-term mortality.

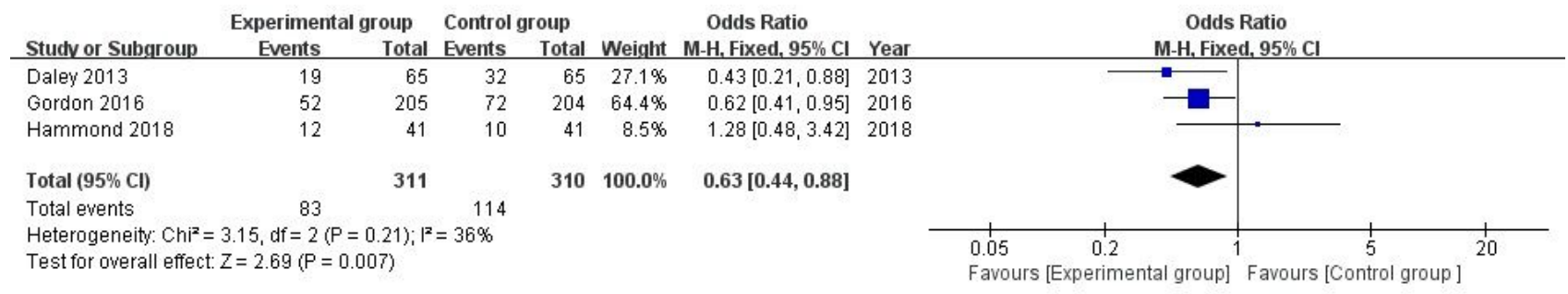

\section{Figure 6}

Forest plot for use of RRT.

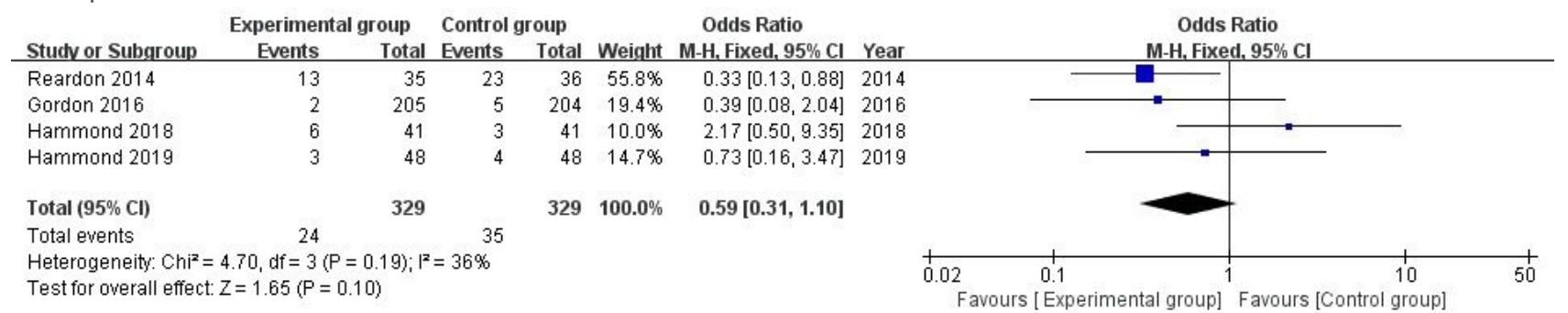

\section{Figure 7}

Forest plot for new onset arrhythmias. 


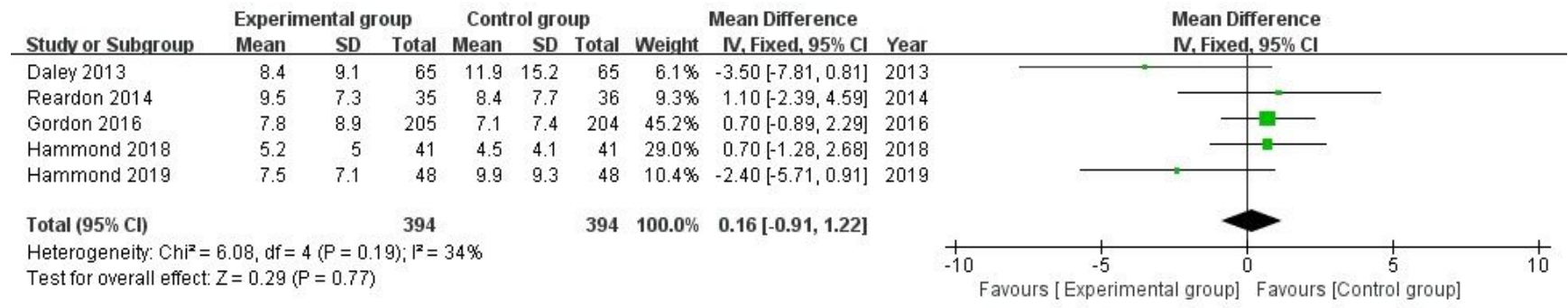

\section{Figure 8}

Forest plot for ICU length of stay.

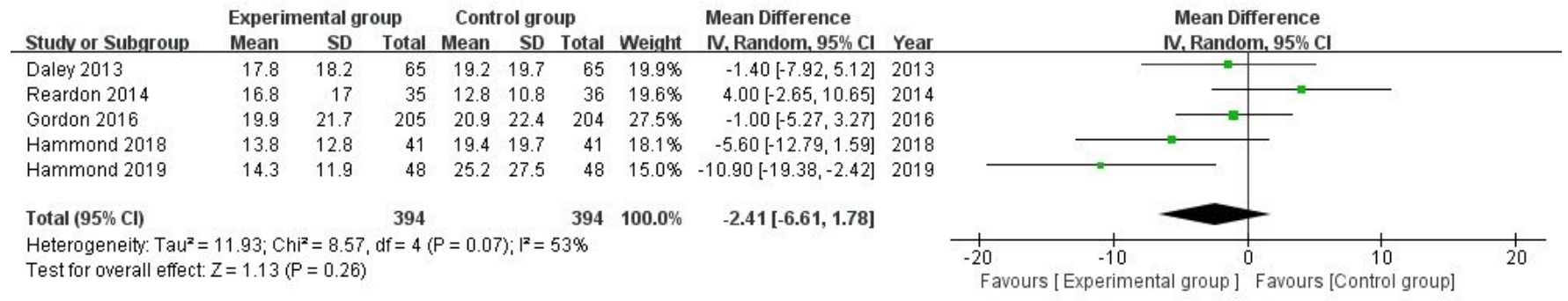

\section{Figure 9}

Forest plot for length of hospitalization. 